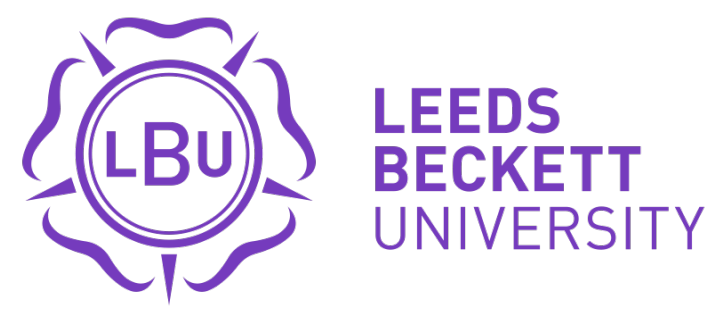

Citation:

$\mathrm{Xu}, \mathrm{L}$ and Zhang, $\mathrm{H}$ and Cuskelly, DD and Doyle, S and Perrett, S and Jones, GW (2021) Mutational analysis of the Hsp70 substrate-binding domain: Correlating molecular-level changes with in vivo function. Molecular Microbiology. ISSN 1365-2958 DOI: https://doi.org/10.1111/mmi.14671

Link to Leeds Beckett Repository record:

https://eprints.leedsbeckett.ac.uk/id/eprint/7490/

Document Version:

Article (Accepted Version)

This is the peer reviewed version of the following article: $\mathrm{Xu}, \mathrm{L}$, Zhang, $\mathrm{H}$, Cuskelly, DD, Doyle, S, Perrett, S, Jones, GW. Mutational analysis of the Hsp70 substratebinding domain: Correlating molecularlevel changes with in vivo function. Mol Microbiol. 2021, which has been published in final form at https://doi.org/10.1111/mmi.14671. This article may be used for non-commercial purposes in accordance with Wiley Terms and Conditions for Use of Self-Archived Versions.

The aim of the Leeds Beckett Repository is to provide open access to our research, as required by funder policies and permitted by publishers and copyright law.

The Leeds Beckett repository holds a wide range of publications, each of which has been checked for copyright and the relevant embargo period has been applied by the Research Services team.

We operate on a standard take-down policy. If you are the author or publisher of an output and you would like it removed from the repository, please contact us and we will investigate on a case-by-case basis.

Each thesis in the repository has been cleared where necessary by the author for third party copyright. If you would like a thesis to be removed from the repository or believe there is an issue with copyright, please contact us on openaccess@leedsbeckett.ac.uk and we will investigate on a case-by-case basis. 


\section{Mutational analysis of the Hsp70 substrate-binding domain: correlating molecular-level changes with in vivo function}

Linan Xu' ${ }^{1}$, Hong Zhang ${ }^{2}$, Daragh D. Cuskelly ${ }^{1}$, Sean Doyle ${ }^{1}$, Sarah Perrett ${ }^{2,3}$, Gary W. Jones $^{1,4 *}$

${ }^{1}$ Department of Biology, Maynooth University, Maynooth, Co. Kildare, Ireland.

${ }^{2}$ National Laboratory of Biomacromolecules, CAS Center for Excellence in Biomacromolecules, Institute of Biophysics, Chinese Academy of Sciences, Beijing 100101, China.

${ }^{3}$ University of the Chinese Academy of Sciences, Beijing 100049, China.

${ }^{4}$ Current address- Centre for Biomedical Science Research, School of Clinical and Applied

Sciences, Leeds Beckett University, Portland Building, City Campus, Leeds LS1 3HE, United Kingdom.

${ }^{*}$ Correspondence to Gary W Jones, Centre for Biomedical Science Research, School of Clinical and Applied Sciences, Leeds Beckett University, Portland Building, City Campus, Leeds LS1 3HE, United Kingdom. Email: gary.jones@leedsbeckett.ac.uk

The authors declare no conflicts of interest.

All materials used in this study are freely available by request to the corresponding author. 


\begin{abstract}
Hsp70 is an evolutionarily conserved chaperone involved in maintaining protein homeostasis during normal growth and upon exposure to stresses. Mutations in the $\beta 6 / \beta 7$ region of the substrate-binding domain (SBD) disrupt the SBD hydrophobic core resulting in impairment of the heat-shock response and prion propagation in yeast. To elucidate the mechanisms behind Hsp70 loss of function due to disruption of the SBD, we undertook targeted mutational analysis of key residues in the $\beta 6 / \beta 7$ region. We demonstrate the critical functional role of the F475 residue across yeast cytosolic Hsp70-Ssa family. We identify the size of the hydrophobic side chain at 475 as the key factor in maintaining SBD stability and functionality. The introduction of amino acid variants to either residue 475 , or close neighbour 483, caused instability and cleavage of the Hsp70 SBD and subsequent degradation. Interestingly, we found that Hsp70-Ssa cleavage may occur through a vacuolar carboxypeptidase (Pep4)-dependent mechanism rather than proteasomal. Mutations at 475 and 483 result in compromised ATPase function, which reduces protein re-folding activity and contributes to depletion of cytosolic Hsp70 in vivo. The combination of reduced functionality and stability of Hsp70-Ssa results in yeast cells that are compromised in their stress response and cannot propagate the $\left[\mathrm{PSI}^{+}\right]$prion.
\end{abstract}

Keywords: Hsp70; substrate-binding domain; prion; heat shock; protein-folding; protein cleavage; Pep4 


\section{Introduction}

Heat shock proteins are critical components of in vivo defence mechanisms against physical and chemical stresses. Hsp70, a universal and highly conserved 70-kDa heat shock protein, is the central hub of this protein quality control network. Structural studies demonstrate that Hsp70 is comprised of two domains: a $45 \mathrm{kDa}$ N-terminal nucleotidebinding domain (NBD) and a $25 \mathrm{kDa}$ C-terminal substrate-binding domain (SBD) (1-3). The NBD consists of two $\alpha$-helix-rich lobes with a deep ATP-binding cleft between them and confers ATP hydrolysis activity to Hsp70s (1). The SBD consists of a $\beta$-sheet-rich substrate-binding site $(\operatorname{SBD} \beta)$, a flexible $\alpha$-helical lid domain $(\operatorname{SBD} \alpha)$ that restricts access to the cavity by docking onto $\operatorname{SBD} \beta(2,4)$, and a C-terminal unstructured tail region mediating substrate capture $(3,4)$. NMR studies suggest that after ADP binding the NBD and SBD connect only through a flexible linker region and without any other intimate contacts (5). In contrast, ATP binding leads to a rearrangement of the entire structure and formation of an interface between the NBD and SBD that results in decreased substratebinding affinity of the $\operatorname{SBD}(6,7)$. The docking of the SBD onto the NBD not only opens up the substrate-binding site of the SBD, but also locks the rotation of NBD lobes and compromises ATP hydrolysis (7). It is thus proposed that there is a bidirectional allosteric intra-molecular regulation between the NBD and SBD.

Hsp70 is able to interact with hydrophobic stretches of proteins to assist protein folding and refolding, and thus protects cells from a variety of stresses $(7,8)$. A recent study highlighted the versatility of the DnaK (E. coli Hsp70) protein, through the identification of approximately 700 substrates (9). This versatility depends on: 1) a tweezers-like functioning of the SBD, which interacts with broad degenerate sequence 
motifs; 2) substrate interactions that are mediated by a complex allosteric mechanism that coordinates ATP hydrolysis of the NBD; 3) J-domain proteins (such as Hsp40, Ydj1) and NEFs (nucleotide exchange factors) that regulate the allosteric mechanism of Hsp70 (7). Deciphering the allosteric mechanism behind substrate-binding in the SBD is a key component in understanding the versatility of Hsp70 chaperone function.

Hsp70 proteins are highly conserved across species. Saccharomyces cerevisiae is a well-established model for studying Hsp70, with the major cytosolic activity provided by the Hsp70-Ssa family (Ssa- Stress Seventy subfamily A). The Hsp70-Ssa family consists of four members (Ssa1-4) (10). Ssa1-2 are constitutively expressed, with Ssa1 upregulated on exposure to stress, while Ssa3 and 4 are only expressed under stress conditions (11). In addition to their role in responding to stress, the Hsp70-Ssa family are important regulators in the propagation of the yeast $\left[\mathrm{PSI}^{+}\right]$prion. $\left[\mathrm{PSI}^{+}\right]$is the prion form of the Sup35 protein, a translation termination factor that has been extensively studied in relation to the influence of chaperones on its occurrence and propagation (12-15). Since the discovery of prions in yeast (16) protein chaperones have been identified as key modulators of prion propagation (17). Hsp104 was the first identified protein shown be essential to maintain propagation of $\left[\mathrm{PSI}^{+}\right]$(18). The Hsp70 chaperone machinery, including Hsp40s, has since been characterised as working in combination with Hsp104 to maintain prion seed availability for transmission to daughter cells and also maintaining the size of prion aggregates in vivo (19). Additional flexibility in prion propagation and in maintaining the heat shock response is achieved through functional differences within the highly homologous Hsp70-Ssa family $(10,20,21)$. As well as assessing factors that influence prion propagation, yeast is also well-established as a model organism for studying protein misfolding diseases such as 
Huntington's, Alzheimer's and Parkinson's, with genetic screens proving highly valuable for identifying novel cellular factors influencing these diseases (22).

Genetic and biochemical studies in yeast have identified many mutations of Hsp70 (Ssa1) that have the ability to impair propagation of yeast prions and/or influence cell growth, with the majority being located in the ATPase domain $(14,23)$. L483W was the first mutant located within the SBD to be well-characterized that impairs prion propagation and the heat shock response $(13,24)$. Recently, residue L484 in the SBD of DnaK (homologous to L483 in yeast Ssa1) has been shown to play a critical role in the regulation of signal transduction from the SBD to the NBD (25). Similarly, we identified another SBD variant, $\mathrm{F} 475 \mathrm{~S}$, which mediates $\left[\mathrm{PSI}^{+}\right]$propagation and the heat-shock response in a similar, but more dramatic way as L483W (24). F475S and L483W are located in $\beta 6$ and $\beta 7$ regions respectively in the SBD. Considering they are close neighbours within the 3D structure of the SBD, we proposed that the $\beta 6 / \beta 7$ region of the Hsp70 substrate-binding domain is a key mediator of the heat-shock response and prion propagation in vivo (24).

Here we further investigate the key role of the $\beta 6 / \beta 7$ region of the SBD domain of Hsp70 in determining functionality. We assess the in vivo structural and molecular characteristics of the $\beta 6 / \beta 7$ region of SBD through targeted mutational analysis of F475 and L483. We found that the size of the hydrophobic side chain on residue 475 is the key factor in determining structural integrity of the $\beta 6 / \beta 7$ region. Interestingly, we identified the vacuolar carboxypeptidase (Pep4) as the possible route for Hsp70-Ssa protein cleavage/degradation rather than the proteasome. Our results confirm our previous finding that mutations at F475 and L483 cause changes to ATPase and protein folding abilities that ultimately compromise the stress response and prion propagation. Our findings suggest that 
109 the $\beta 6 / \beta 7$ region is a key mediator, and perhaps the central hub, for determining structural 110 integrity and functionality of the Hsp70 SBD and identify this region of the protein, either 111 directly or indirectly, as a possible druggable target. 


\section{Materials and Methods}

Plasmids and yeast strains

The SSA1 gene and desired mutations were constructed in pC210 plasmid (SSA1 under own promoter with $L E U 2$ marker) $(24,26,27)$. Plasmids were transformed into strain G402 (MATa ade2-1 SUQ5 karl-1 his3 leu2 lys2 trp1 ura3 ssa1:: KanMX, ssa2::HIS3, ssa3::TRP1, ssa4::ura3-1f/pRDW10) (28), and cells that had retained the pRDW10 (SSA1 under own promoter) URA3 plasmid containing wild-type Ssa1were selected against by restreaking transformed cells onto plates containing 5-fluoroorotic acid (5-FOA). The ade21 allele is a nonsense mutation in the $A D E 2$ gene that causes the build-up of red pigment in yeast colonies. The presence of the yeast prion $\left[\mathrm{PSI}^{+}\right]$results in reduced levels of translation termination at nonsense mutations and there for causes a high level of readthrough of ade2-1. The result is functional Ade2 protein and no build-up of the red pigment. Hence, $\left[\mathrm{PSI}^{+}\right]$colonies appear white on complete medium with limiting adenine and can grow on medium lacking adenine, while $\left[p s i^{-}\right]$cells are red and require adenine supplementation to grow.

Yeast growth assay

Yeast strains were cultured in $5 \mathrm{ml} \mathrm{YPD}$ or SC with appropriate selection at $30^{\circ} \mathrm{C}$ overnight. The following morning, the yeast cultures were diluted to an $\mathrm{OD}_{600}$ of 0.2 , and grown until the $\mathrm{OD}_{600}$ reached 0.5 . A $1 / 5$ serial dilution was performed in a 96-well plate and then replicated onto appropriate media. Plates were incubated at $30^{\circ} \mathrm{C}$ or elevated temperatures $\left(37^{\circ} \mathrm{C}\right.$ or $39^{\circ} \mathrm{C}$ ) for 2 days as required.

Protein purification 
Full-length Ssa1 (residues 2-642), truncated Ssa1 (residues 382-554) and corresponding mutations were purified as previously described (24). Briefly, full-length Ssal and mutations were firstly purified on a Ni affinity column (GE Healthcare) in $50 \mathrm{mM}$ Tris buffer (pH 7.5), $300 \mathrm{mM} \mathrm{NaCl}$ and $3 \mathrm{mM} \beta$-mercaptoethanol. Following Ulp1 cleavage to remove the N-terminal His-Smt3 tag and a second Ni affinity column purification, the flow through including tag-free protein was further purified by gel filtration chromatography (Superdex 200, GE Healthcare) in $50 \mathrm{mM}$ Tris buffer (pH 7.5), $100 \mathrm{mM} \mathrm{KCl}$ and $5 \mathrm{mM}$ $\mathrm{MgCl}_{2}$. The truncation mutants were similarly purified with some modifications to buffers. For Ni affinity purification, $50 \mathrm{mM}$ Tris buffer (pH 8.0) and $200 \mathrm{mM} \mathrm{NaCl}$ was used. Gel filtration chromatography was performed in $50 \mathrm{mM}$ Na-phosphate buffer ( $\mathrm{pH} 7.0$ ) with 50 $\mathrm{mM} \mathrm{NaCl}$ (Superdex 75, GE Healthcare).

Circular dichroism spectroscopy

The CD spectra of full-length Ssa1 and mutations were obtained in $50 \mathrm{mM}$ Tris buffer $(\mathrm{pH}$ 7.5), $100 \mathrm{mM} \mathrm{KCl}$ and $5 \mathrm{mM} \mathrm{MgCl} 2$ at a protein concentration of $3 \mu \mathrm{M}$ using a Chirascan Plus CD spectrometer (Applied Photophysics, UK). Spectra were measured from 200 to $260 \mathrm{~nm}$ in a $10 \mathrm{~mm}$ path-length thermostat-controlled quartz cuvette. The temperature was controlled using a Peltier device. The truncation mutants, at a protein concentration of 10 $\mu \mathrm{M}$, were measured in $50 \mathrm{mM}$ Na-phosphate buffer ( $\mathrm{pH} 7.0$ ) with $50 \mathrm{mM} \mathrm{NaCl}$.

Size exclusion chromatography (SEC)

Recombinant proteins were incubated at RT for $0 \mathrm{~h}$ or $24 \mathrm{~h}$ The pattern and degradation of SBD truncation mutants were evaluated by SEC (Superdex 75, $24 \mathrm{ml} \mathrm{GE} \mathrm{Healthcare)} \mathrm{in}$ $50 \mathrm{mM}$ Na-phosphate buffer (pH 7.0) with $50 \mathrm{mM} \mathrm{NaCl}$ at RT. 
ATPase assay

The ATPase activity was measured based on colorimetric determination of inorganic Naphosphate using malachite green as previous described $(24,29)$. Briefly, $10 \mu \mathrm{l}$ of $2 \mu \mathrm{M}$ Ssa1 (50 mM Tris pH 7.5, $100 \mathrm{mM} \mathrm{KCl,} 5 \mathrm{mM} \mathrm{MgCl} 2$ and $1 \mathrm{mM}$ DTT) was added with $10 \mu \mathrm{l}$ of $2 \mathrm{mM}$ ATP into each well of a 96-well plate, and then incubated for $5 \mathrm{~h}$ at the indicated temperature. If $\mathrm{Ydj} 1$ or peptide (ALLLSAPRR) was required, a final concentration of $8 \mu \mathrm{M}$ or $400 \mu \mathrm{M}$ was used, respectively.

Luciferase refolding assay

The luciferase assay was carried out as previously described (24). Briefly, overnight cultures were diluted to an $\mathrm{OD}_{600}$ of 0.2 in SC media without uracil (SC-URA) and incubated at $37^{\circ} \mathrm{C}$ with shaking for 30 min to induce expression of heat shock proteins. After culturing, the cellular luciferase activity of each strain was measured by immediately adding $10 \mu \mathrm{l}$ of decanal (Sigma) to $200 \mu \mathrm{l}$ of culture in a FB12 Luminometer (Berthold Detection Systems) as a reading for $100 \%$ activity. Cells were then transferred into a $45^{\circ} \mathrm{C}$ shaking incubator for $1 \mathrm{~h}$. During this $1 \mathrm{~h}$ heat shock, cycloheximide (Sigma) was added after $50 \mathrm{~min}$ at $10 \mu \mathrm{g} / \mathrm{ml}$. After thermal denaturation at $45^{\circ} \mathrm{C}$, cellular luciferase activity was measured as the starting point $(\mathrm{t}=0)$. Cultures were shifted to $25^{\circ} \mathrm{C}$ at intervals of 15 min for a duration of $1 \mathrm{~h}$. The luciferase recovery ratio was calculated based on the starting point $(\mathrm{t}=0)$ and ending point after $1 \mathrm{~h}$ recovery as a percentage of the $100 \%$ activity.

Protein extraction from yeast

Yeast strains were cultured overnight in $5 \mathrm{ml} \mathrm{YPD}$ or selective media at $30{ }^{\circ} \mathrm{C}$. The following morning, cells were diluted in $25 \mathrm{ml}$ fresh same media to an $\mathrm{OD}_{600}$ of 0.2 and 
incubated until an $\mathrm{OD}_{600}$ of $0.6-0.8$ was reached. Washed cell pellets were resuspended in yeast cell lysis reagent (Sigma C4482) complemented with $10 \mathrm{mM}$ DTT and protease inhibitor cocktail (Sigma P8215). Glass beads of $0.5 \mathrm{~mm}$ were used to aid cell lysis using a MiniBeadbeater (Biospec products). For inhibitor treatments, the fresh WT/F475S cells were cultured at $30^{\circ} \mathrm{C}$ in SC containing $0.1 \%$ (w/v) L-Proline to $\mathrm{OD}_{600} 0.5$, then cells were harvested and resuspended in $20 \mathrm{ml}$ of fresh SC with $0.003 \%$ (w/v) SDS containing $75 \mu \mathrm{M}$ MG132 or $1 \mathrm{mM}$ PMSF for another $2 \mathrm{~h}$ incubation at $30{ }^{\circ} \mathrm{C}$ before harvesting and homogenization.

Immunoprecipitation

Anti-Flag M2 Magnetic Beads (Sigma) were used to purify Flag-tagged Ssa1 in yeast cells. A $300 \mu \mathrm{g}$ sample of protein was extracted and incubated with $20 \mu 1$ Magnetic Beads with gentle rotation at $4{ }^{\circ} \mathrm{C}$ overnight. Magnetic Beads were collected using a magnetic separator and washed with 10 volumes of TBS (50 mM Tris- $\mathrm{HCl}, 150 \mathrm{mM} \mathrm{NaCl}, \mathrm{pH} 7.5)$ four times followed by the addition of three volumes of $3 \times$ Flag peptide of $150 \mathrm{ng} / \mu 1$ and incubation on a rotator for $1 \mathrm{~h}$ at $4{ }^{\circ} \mathrm{C}$. Supernatants were transferred to pre-chilled $1.5 \mathrm{ml}$ microfuge tubes and centrifuged (10 min, $13000 \mathrm{rpm})$. Then $25 \mu 1$ was analyzed by Western blotting.

\section{Cleavage assay}

For SBD cleavage assay under heat shock or AZC treatments, G402 strains were cultured in $6 \mathrm{ml}$ YPD media overnight at $30^{\circ} \mathrm{C}$ with shaking. The following morning, part of the overnight cultures were diluted in $25 \mathrm{ml} \mathrm{SC}$ containing $300 \mu \mathrm{g} / \mathrm{ml} \mathrm{AZC}$ to an $\mathrm{OD}_{600}$ of 0.2 . For the heat shock treatment, overnight cultures were diluted in $25 \mathrm{ml}$ YPD media to an 
$\mathrm{OD}_{600}$ of 0.2 . When an $\mathrm{OD}_{600}$ of 0.5 was reached, untreated and $\mathrm{AZC}$ treated cells were kept at $30^{\circ} \mathrm{C}$ and the other cells were heat shocked at $39^{\circ} \mathrm{C}(2 \mathrm{~h}$ or $3 \mathrm{~h})$. Protein extraction, immunoprecipitation and Western blot were performed to investigate the cleavage of Ssa1 and its mutations.

Molecular dynamics (MD) simulation

MD simulations were performed using the GROMACS 4.5.7 and 4.6 package (32) as described previously (27). The homologous Hsp70 solution structure of Ssa1, DnaK SBD with peptide NRLLTG (PDB code: 1Q5L) (33) was used as wild type. Appropriate mutants were constructed using Swiss-Pdb Viewer (34) based on wild type. Simulations were carried out over a $20 \mathrm{~ns}$ period at $300 \mathrm{~K}, \mathrm{pH} 7.0$ and 1 bar pressure. The coordinate trajectories were saved for subsequent data analysis.

Statistical analysis

Student's t-test was used, where appropriate, for statistical analysis. Sample sizes used were in line with other similar published studies. Data are presented as mean \pm SD. Statistical analysis was performed using the statistical software package GraphPad Prism v6 or Microsoft EXCEL. $\mathrm{P} \leq 0.05$ was considered statistically significant. 


\section{Results}

Evolutionarily conserved F475 mediates function in the Hsp70-Ssa family

The F475S variant of Ssal has been characterised as impairing both the heat shock response and $\left[\mathrm{PSI}^{+}\right]$propagation (24). However, whether this is the case for the whole Hsp70-Ssa family has not been determined. F475 is highly conserved among the Hsp70 family of proteins, not only in yeast, but also in human and E. coli homologues (Fig. 1A). F475 is found to be the most conserved residue situated in $\beta 6$ and is proximal to the hydrophobic core of the SBD (Fig. 1A and 1B).

To further investigate the role of F475 in the Ssa subfamily, the F475S mutation was introduced into Ssa2-Ssa4, and phenotypically assessed with these mutants providing the sole source of cytosolic Hsp70 in vivo. Similar to Ssa1 ${ }^{\mathrm{F} 475 \mathrm{~S}}$, $\mathrm{Ssa}^{\mathrm{F} 475 \mathrm{~S}}$ and $\mathrm{Ssa}^{\mathrm{F} 475 \mathrm{~S}}$ are unable to propagate $\left[\mathrm{PSI}^{+}\right]$and are compromised for the heat shock response (Fig. $1 \mathrm{C}$ and 1D). Interestingly, $\mathrm{Ssa} 3^{\mathrm{F} 475 \mathrm{~S}}$ is lethal to the cell and further highlights the significance of F475 in maintaining Hsp70 function.

F475S destabilizes Ssal and results in SBD cleavage and degradation

F475S was proposed to disrupt the hydrophobic core of the SBD and shown to result in degradation in vitro (24). To further confirm whether SBD break down occurs in full-length Ssa1, N-terminal Flag-tagged wild-type Ssa1 and its F475S mutant were expressed in G402 cells as the sole source of cytosolic Hsp70, and then enriched by immunoprecipitation. Figure 2A, shows several bands observed around 40-50 kDa in the Flag-F475S sample, 
which are absent in the wild-type sample. Considering the Flag tag was fused to the Nterminal of Ssa1 and the size of the NBD is around $45 \mathrm{kDa}$, the cleavage bands of the FlagF475S suggested that the SBD is readily degraded and results in the production of NBD fragments in vivo or at least in the cell lysate.

Proteins are degraded by two alternative breakdown pathways in $S$. cerevisiae. Usually, the degradation of short-lived proteins happens in proteasomes and can be inhibited by carbobenzoxyl-leucinyl-leucinyl-leucinal (MG132); vacuolar proteases contribute to degrading long-lived proteins and can be suppressed by phenylmethylsulfonyl fluoride (PMSF) (35). To distinguish between the cytosolic vs vacuolar proteolytic pathway contribution to SBD cleavage/degradation, we added each class of inhibitor separately into cultures to prevent protein degradation. Western blotting showed that the basal Ssa1 level of F475S was comparable with DMSO treatment after MG132 inhibitor incubation but enhanced after treatment with PMSF (Fig. 2B), suggesting SBD cleavage/degradation mainly occurred by the vacuolar proteinase rather than proteasomal. To confirm this hypothesis, we assessed the SBD cleavage of the F475S variant in three knockout strains, $\triangle P E P 4$ (vacuolar carboxypeptidase deficient), $\triangle U F D 2$ (ubiquitin fusion degradation factor deficient) and $\triangle U B I 4$ (ubiquitin precursor deficient) by transforming the Flag-tagged F475S variant into each of these three backgrounds. Cells were then cultured in SC-Leu, and Flag-Ssal was enriched using anti-Flag beads. As shown in Figure $2 \mathrm{C}$, the abundance of full-length F475S variant was signifcantly increased in $\triangle P E P 4$ with corresponding reduced levels of cleavage products. Both $\triangle U F D 2$ and $\triangle U B I 4$ do not significantly reverse the cleavage pattern. This result clearly shows that the major 
proteolysis for Hsp70 cleavage due to F475S structural perturbation, may be through a Pep4 [vacuolar carboxypeptidase]-dependent mechanism.

Size of the hydrophobic amino acid side chain at residue F475 is the predominant determining factor for impairing Hsp70 function in vivo

To investigate the key molecular factors that determine Hsp70 functional change caused by perturbation of the $\beta 6 / \beta 7$ region, we created a variety of amino acid substitutions at F475 and characterized these genetically and biochemically (Table 1). It was found that hydrophobic residues phenylalanine (F) and tyrosine (Y) maintained Hsp70 cellular functions relating to $\left[\mathrm{PSI}^{+}\right]$propagation and heat-shock response, but hydrophilic serine (S) resulted in severe $\left[\mathrm{PSI}^{+}\right]$impairment and temperature sensitivity (Fig. 3A, 3B and 3D). The impact of serine at this residue resulted in hydrophobic-core disruption caused by introducing the hydrophilic side chain (24). Notably, decreasing the size of hydrophobic side chain of residue 475 to very small alanine (A) resulted in $\left[P S I^{+}\right]$impairment but very limited temperature sensitivity suggesting the hydrophobic alanine (A) may be too small to fill the hydrophobic cavity around residue 475 (Fig. 3A, 3B and 3D). Moreover, at the other extreme, the window for increasing the hydrophobic size of the amino acid is also narrow as replacing phenylalanine $(\mathrm{F})$ or tyrosine $(\mathrm{Y})$ with tryptophan $(\mathrm{W})$ resulted in a non-functional Hsp70 and cell nonviability (Table 1), which may be due to catastrophic disruption of the hydrophobic core (Fig. 3A, 3B and 3D). Surprisingly, Cysteine (C) substitution compared to serine (S) did not display similar phenotypes, but was more similar to WT (Fig. 3A, 3B and 3D). This could suggest that Cysteine (C) substitution at 
F475 influences Ssa1 function through a complicated mechanism rather than disrupting the hydrophobic core only. These phenotypic trends are also observed for other cellular stresses such as cell wall damage (SDS) and oxidative damage $\left(\mathrm{H}_{2} \mathrm{O}_{2}\right)$ (Fig. $\left.3 \mathrm{C}\right)$. Also, exposure to higher concentrations of oxidative damage revealed a phenotypic difference between $\mathrm{F}$ and all other mutations (Fig. 3C), which reflects the importance of this highly conserved residue in this region (Fig. 1A).

The side chain of residue at position 475 is a key mediator of SBD stability

We previously reported that the F475S mutation in Hsp70 results in unfolding of the SBD and accelerates protein degradation (24). To evaluate the molecular level changes that induce SBD unfolding and subsequent degradation, we employed size exclusion chromatography (SEC) and circular dichroism (CD) to monitor the effects of F475 substitutions on protein conformation and secondary structure. Comparing to standards (Fig. S3), Figure 4A demonstrates that F475A, F475C and F475Y maintain the monomeric state similar to WT, but the lethal mutant F475W had an obvious absorbance shift towards F475S. As F475S had been confirmed to cause unfolding of the SBD rather than oligomerization (24), it was considered that F475W exhibited similar behaviour but maybe to a different degree. After a $24 \mathrm{~h}$ incubation at room temperature, there was no aggregated protein observed after centrifugation $(13,000 \mathrm{~g}, 10 \mathrm{~min})$, but we clearly observed a decrease in absorbance at the elution peak and a continuous increase in absorbance after the peak, suggesting that both F475S and F475W are less stable and cleaved into smaller fragments in vitro compared with other F475 substitutions (Fig. 4B). Consistent with these findings, both F475W and F475S exhibited a disrupted secondary structure in their CD spectra (Fig. 4C). Although F475A did not display significant unfolding at $30^{\circ} \mathrm{C}$, we did observe that 
F475A caused SBD unfolding and reduced stability compared to wild type at elevated temperature (Fig. S1), which reflects the milder impairment phenotypic stress response we compared to the S mutation (Fig. 3B-3D). CD spectra of the full-length Ssal proteins shows that F475S and F475W have similar characteristics (Fig. 4D). F475S and F475W variants do show a decreased absorbance at 215-217 nm, which reflects loss of $\beta$-sheet structure in SBD $\beta$ (Fig. 4D). Additionally, both mutants caused changes at $208 \mathrm{~nm}$ and 222 nm compared to WT (Fig. 4D), which reflects some conformational change in the $\alpha$-helical regions in the NBD (24).

\section{Substitutions at residue 475 alter critical functions of Hsp70}

Of critical importance to maintaining Hsp70 functionality is regulation of its ATPase activity. We therefore assessed the ATPase hydrolysis activity of each full-length F475 mutant under various conditions. F475S increased the basal ATPase activity, but was incapable of further stimulation by Ydj1, this trend was seen over three temperature ranges (Fig. 5A). Notably, heat shock significantly increased the basal ATPase activity of WT, but not F475S (Fig. 5A). It has been shown that the SBD acts as a "brake" on the NBD's ATPase activity and that the free NBD with the linker domain attached has a higher ATPase activity than full-length Hsp70 (37). Thus, one possible reason for enhanced ATPase activity is that heat shock causes perturbation of the SBD which leads to a reduction in SBD-mediated repression of ATPase activity of the NBD. To investigate whether SBD cleavage occurred after heat shock, we enriched flag-tagged Ssal from cell lysate to minimize protein-level influence caused by heat shock and detected Ssa1 fragments as Fig. 
2A. Interestingly, degraded fragments of Hsp70 of approximately $45 \mathrm{kDa}$ can be observed from cells exposed to heat shock, suggesting SBD undergoes cleavage under these conditions in vivo or at least in cell lysis (Fig. 5D, left panel). Additionally, this observation was confirmed using a heat-shock mimetic compound azacytidine (AZC) (Fig. 5D, right panel). Similar to F475S (24), F475W significantly increased ATPase activity at $30^{\circ} \mathrm{C}$ (Fig. 5B). In contrast, F475A has a small effect on basal ATPase activity and $\mathrm{F} 475 \mathrm{C} / \mathrm{Y}$ are similar to WT (Fig. 5B). Notably, the ATPase activity of F475W is also not stimulated by Ydj1 (Fig. 5B). Additionally, F475S/W, but not F475A/C/Y, showed compromised ATP hydrolysis stimulated by peptide binding (Fig. 5C). The elevated basal ATPase rate by SBD mutants (especially F475W and F475S) and compromised ATP stimulation by client binding implies that SBD disruption abolishes the inhibition of ATP hydrolysis of NBD.

The Hsp70/Hsp40/Hsp104 machinery plays an essential role in protein folding and the heat-shock response. Previously we demonstrated that F475S is deficient in luciferase refolding (24). Unsurprisingly, the F475A mutation, which also exhibits a [psi $]$ phenotype, had reduced ability to refold denatured luciferase, and $\mathrm{F} 475 \mathrm{C} / \mathrm{Y}$ displayed a comparable refolding activity with WT (Fig. 6A). Additionally, we assessed the abundance of selected chaperones and found that Hsp104 and Ydj1 were expressed at similar levels in WT and all mutants. However, we observed a variant pattern in abundance of Ssal within the mutants. Surprisingly, F475C, which had no dramatic phenotypic effects, exhibited greatly reduced levels of Ssa1 that were similar to F475S (Fig. 6B), while F475A, which exhibits the most similar phenotypic profile to F475S, in contrast to this mutant, expressed high levels of Ssal (Fig. 6B). 
Substitutions at residue 483 alter critical functions of Ssa1

In addition to $\mathrm{F} 475, \mathrm{~L} 483$ also located in the $\beta 6 / \beta 7$ region has been reported and characterised as impairing $\left[\mathrm{PSI}^{+}\right]$propagation $(24,27)$. Furthermore, using steered molecular dynamics simulations, it is possible to predict prion propagation phenotypes when introducing mutations at L483 (27). We find that amino acids with a large side chain $(\mathrm{L} 483 \mathrm{~W} / \mathrm{H})$ at this residue not only impaired $\left[\mathrm{PSI}^{+}\right]$propagation (27), but also compromise thermotolerance (Fig. 7A). Similar to F475S, both L483W and L483H display a deficiency in luciferase refolding activity (Fig. 7B), each have elevated basal ATPase activity and compromise stimulation by Ydj1 and peptide (Fig. 7C). Additionally, there are no significant differences in Hsp104 and Ydj1 expression, but decreased Ssa1 abundance is observed for L483W and particularly for L483H (Fig. 7D).

\section{Substitutions at residue 483 alter stability of the SBD}

We evaluated the influence of substitution mutations at residue 483 upon conformation and stability, by obtaining CD spectra of purified SBD mutants. L483W/H exhibited decreased absorbance at 215-217 nm compared to WT, which implies a loss of $\beta$-sheet structure in the SBD $\beta$ (Fig. 8A), although not to the same extent as F475S/W (Fig. 4C). Additionally, compromised $\beta$-sheet content can be observed from full-length proteins for $\mathrm{L} 483 \mathrm{~W} / \mathrm{H}$ and both mutants have reduced absorbance at $208 \mathrm{~nm}$ and $222 \mathrm{~nm}$ suggesting a structural change within the NBD also (Fig. 8B) (24), which may explain the enhanced ATPase of L483W/H variants. Molecular simulations were employed to assess what may happen once the large side chain was introduced at residue 483 . Simulations predict that the larger side 
chain of $\mathrm{W}$ and $\mathrm{H}$, compared to $\mathrm{L}$ or $\mathrm{A}$, could easily perturb the microenvironment by infiltrating the hydrophobic core (Fig. 8C and 8D). As a consequence, the SBD of L483W/H may induce the same mechanism that unfolds the SBD and results in an instability profile similar to the F475S/W mutants (Fig. S2, 4A, 4B, 4C, and 8A). In particular $\mathrm{L} 483 \mathrm{H}$, exhibits the most severe thermotolerance phenotype and has the most extreme effects on abundance and predicted structural perturbation (Fig. 7A, 7D, 8A and S2).

\section{Discussion}

The essential role Hsp70 plays in protein folding and in survival following exposure to a variety of stresses, has been demonstrated in a number of species $(31,39-41)$. The key to Hsp70 functionality is the coordination and communication between the NBD and SBD (7). Recent studies have identified amino acid residues in the SBD that play critical roles in signal transduction to the NBD (25) and highlight the $\beta 6 / \beta 7$ region as an important mediator of peptide binding and structural stability (24). Within the $\beta 6 / \beta 7$ region the two highly conserved residues are F475 and L483 (residue numbers from yeast Ssa1 protein) (Fig. 1A). The importance of these residues has been isolated in studies using yeast, when mutants of both residues, namely F475S and L483W, have been isolated from genetic screens that identified Hsp70 mutants that impaired prion propagation $(13,24)$. The F475S mutation has the most extreme effects on in vivo function in that yeast cells expressing this variant as the sole source of Hsp70-Ssa are unable to propagate the prion state $\left[P S I^{+}\right]$and are unable to tolerate a variety of stresses (24). The main goals of this study were to assess the in vivo consequences of F475S across the Hsp70-Ssa family and to identify the molecular level changes that occur in mutants created at residues 475 and 483 , and correlate 
molecular changes with phenotypic outcome. To assess if the phenotypic effects of F475S are replicated in the Hsp70-Ssa family, we created isogenic yeast strains expressing Ssa1, 2, 3, or 4 variants of F475S as the sole source of cytosolic Hsp70. Given the high degree of sequence identity between members of the Ssa family, it is not surprising that the F475S mutation has major phenotypic effects on all these strains. Ssa1, 2 and 4 proteins harbouring F475S have similar prion propagation and thermotolerance phenotypes (Fig. 1C and 1D), while Ssa $3^{\mathrm{F} 475 \mathrm{~S}}$ cannot maintain cell viability. Presumably Ssa3 is more susceptible than other Ssa proteins to the structural perturbations caused by F475S and hence is degraded more rapidly. While the Ssa family are highly conserved and do exhibit redundant functionality at times, there are many studies that highlight functional differences between family members and in particular Ssa3, a recent example being the identified link between autophagy and Ssa3 (42). It is clear that similar to L483W, which has been shown to exhibit prion impairing effects in different Ssa isoforms $(23,43)$, F475S causes severe loss of function across the whole Hsp70-Ssa family.

Our previous study identified instability of the SBD and unfolding of the $\beta 6 / \beta 7$ region as the primary initiating event and the cause of Hsp70-Ssal loss of function due to F475S (24). To investigate further the molecular level events that occur in the $\beta 6 / \beta 7$ region that lead to functional change in Hsp70, we created a range of amino acid substitution mutations at both 475 and 483, and assayed for functional change through a range of genetic, biochemical and structural techniques. The major finding from this analysis is that the key factor to maintaining or perturbing the structural integrity of the SBD, is the size of the hydrophobic amino acid occupying these two key residue sites. The introduction of hydrophilic Ser or extremely small hydrophobic Ala at 475 causes the greatest phenotypic 
changes and results in loss of $\left[\mathrm{PSI}^{+}\right]$propagation and reduced stress tolerance (Fig. 3A3D). This is because when the extremes of the tolerance boundaries are reached, there is a dramatic change in function and resulting phenotype. This is seen in the loss of prion propagation and thermotolerance through replacement of hydrophobic Phe with very small hydrophobic Ala, and with loss of viability due to replacement of Phe/Tyr with extremely large $\operatorname{Trp}$ (Table 1). Similar to 475, a proper size of hydrophobic side chain is the key factor for functional change at residue 483. Replacement of hydrophobic Leu with either hydrophilic His or extremely large Trp, resulted in loss of $\left[\mathrm{PSI}^{+}\right]$propagation and reduced thermotolerance (Fig. 7A), while replacement with small Ala seems enough to fill the cavity occupied by small Lue in wile-type protein (Fig. 7A).

While Cys and Ser are similar in size, which can result in substitutions displaying similar phenotypic outcomes (44), Cys is much more hydrophobic than Ser and has resulted in differing effects through altering protein conformation and thermostability $(45,46)$. In this study, F475C displayed a dramatically different prion propagation and thermotolerance compared with F475S (Fig. 3A, 3B and 3D). Notably, F475C has a very low abundance like F475S, which suggests a problem with stability (Fig. 6B). However, F475C maintains the folding of SBD well (Fig. 4A and 4C), and appears stable after a $24 \mathrm{~h}$ incubation at RT in vitro (Fig. 4B). It is possible that $\mathrm{F} 475 \mathrm{C}$ causes instability through a mechanism independent from disruption of the SBD. Moreover, cellular functions of Ssa1, such as intrinsic or stimulated ATPase activity (Fig. 5B and 5C) and refolding activity (Fig. 6A), are intact in $\mathrm{F} 475 \mathrm{C}$ variant, suggesting that $\mathrm{F} 475 \mathrm{C}$ may have enhanced chaperone functions, which could compensate for lower abundance. It is clear the introduction of C 
at the 475 residue causes a complex change to the in vitro and in vivo properties of Ssal that we cannot yet fully appreciate and explain in terms of the phenotypic consequences.

Structural analysis of 475 and 483 mutants suggests that changes in amino acid side chain size at these sites results in major conformational changes in the $\operatorname{SBD} \beta$ sub-domain and some conformational change in key regions of the NBD (Fig. 4A-4D and Fig. 8A-8D). We propose that the steric structural constraints within this critical region of the SBD are breached by the introduction of amino acids with hydrophilic or larger hydrophobic side chains than the evolutionary conserved Phe475 or Leu483. Structural disturbance in the $\beta 6 / \beta 7$ region causes localised unfolding of this region that spreads into the binding site and also into the NBD-SBD interface. The consequence of unfolding of the SBD is to instigate Hsp70 degradation from the C-terminal region (24).

Many ubiquitination sites have been identified on $\operatorname{Hsp} 70(49,50)$. Parkin mediates the mono-ubiquitination of Hsp70, but fails to alter its steady-state level and promote its proteasomal degradation (51). However, CHIP (an E3 ubiquitin protein ligase that binds to the carboxy terminus of Hsp70) is capable of targeting Hsp70/Hsc70 for ubiquitination, and results in rapid $26 \mathrm{~S}$ proteasome-dependent degradation in vitro (52). Notably, Hsp70 was much more susceptible to CHIP-mediated proteasome-dependent degradation, whereas only modest degradation was observed for Hsc70 (52), suggesting other E3 ligases target constitutive Hsc70 to trigger proteasome-dependent degradation, or that Hsc70 degradation can occur through another pathway. Additionally, it has been shown that wildtype Ssa1 is rapidly digested into smaller forms, which represents species lacking the whole SBD or the C-terminal lid, and studies indicate that the $45 \mathrm{kDa}$ NBD of Hsp70 is protease resistant whereas the smaller SBD is proteolytically labile $(53,54)$. Recently we showed 
that Ssal denaturation was triggered through unfolding in the $\beta 6 / 7$ region of the SBD and induces protein degradation (24). An interesting finding from this study is that the SBD cleavage/degradation of Hsp70-Ssa1 appears to be Pep4-dependent (Fig. 2A-2C). It has not previously been reported that Ssal is transported into the vacuole or is a substrate of Pep4. While the possibility exists of complications in protein stabilty during the cleavage assay, the clear genetic evidence presented in Figure 2C, suggests this hypothesis is worthy of further investigation.

The proteasome-dependent proteolytic machinery prevents the accumulation of misfolded proteins during heat shock in eukaryotic cells (55). A previous study demonstrated that CHIP mediates a competitive relationship between Hsp70 and misfolded proteins following heat shock by preferentially ubiquitinating chaperone-bound substrates rather than chaperones themselves (52). Therefore, Hsp70 exists as a stable long lived protein (half-life of $20.2 \mathrm{~h}$ ) (56) and the substrate-bound protein is predominantly degraded (52). However, proteasome-dependent degradation is not conserved within all domains of life, which highlights the importance of carboxypeptidase-dependent protein degradation. Intriguingly, there is no CHIP in yeast, so Ssa1 and its misfolded clients may be degraded through other pathways. Additionally, we found that elevated growth temperatures induce instability in the SBD (24), and cleavage of this domain can be observed following a $2 \mathrm{~h}$ heat shock (Fig. 5D). A plausible explanation is that heat shock disrupts the folding of SBD and exposes the cleavage site to proteinases which leads to further degradation. It is also possible that Ssal binding with misfolding substrates accumulated from heat shock, and co-degraded with substrates through a vacuolar-dependent process. 
The prion propagation and thermotolerance phenotypes of the assessed Phe 475 and Leu483 mutants correlate well with the extent of SBD instability each mutant produces, that is, the greater structural instability within the SBD, the more severe the loss of function phenotype. A good correlation is also observed when comparing phenotype with biochemical activity. A trend observed for all Hsp70 mutants that impair prion propagation is an increase in basal ATPase activity with a reduced stimulation following addition of either Hsp40 or peptide (Figs. 5A-5C and 7C) (54). Dysregulation of ATP hydrolysis will result in an uncoordinated action of the NBD and SBD that will impair Hsp70 function. Genetic evidence for this hypothesis comes from the fact that Hsp70 mutants predicted to affect peptide-binding activity can suppress the prion impairment phenotype of L483W (14), and it is further supported by steered molecular dynamics simulations (27). Additionally, we found that mutants with deficiency in luciferase refolding, had the most severe prion propagation (Figs. 6A and 7B).

We find that there is no difference in the abundance of Hsp104 or Ydj1 in any of these mutant strains (Figs. 6B and 7D). However, there is variation in the abundance of Ssa1, with F475S, F475C, L483W and L483H, having low levels of cytosolic Hsp70 (Figs. 6B and 7D). Very low levels of Hsp70 in both prion impaired and prion proficient yeast cells has been observed previously with some F475S suppressor mutations restoring protein abundance levels, and others not (24). It is not possible to draw any conclusions regarding the abundance of Hsp70 in yeast and a resulting prion or thermotolerance phenotype. Very low levels of Hsp70 are required to maintain normal cellular function under unstressed conditions in yeast as there is no major growth phenotype for any viable 475 or 483 mutant. It is alteration of specific Hsp70 functions that results in phenotypic change and, as in 
previous studies (24), the prion propagation phenotype is much more sensitive to these changes compared to other important central cellular functions carried out by Hsp70. This is the case as 475 and 483 mutants that cannot propagate $\left[\mathrm{PSI}^{+}\right]$, do not exhibit other phenotypes under non-stressed conditions. While prion propagation, protein folding and thermotolerance are inherently dependent on the same functional properties of Hsp70, they are distinguishable due to their differing sensitivity to perturbation of Hsp70 function (20).

In this study we provide further evidence to support the hypothesis that the $\beta 6 / \beta 7$ region of the Hsp70 SBD plays a major role in maintaining the structural integrity of the entire domain. We speculate that disruption of the SBD results in an equilibrium shift to the unbound state, which allows the NBD subdomains to rotate to a degree where the catalytic residues in the ATPase active centre reach the optimal position for $\gamma$-phosphate cleavage (57). As a consequence, in the 475 and 483 mutants that are destabilized, the SBD inhibition of ATP hydrolysis is abolished. The fact that loss of Hsp70 function causes a gradation of phenotypic responses, with essential cellular functions being least affected, supports the notion that Hsp70 is a druggable target and the $\beta 6 / \beta 7$ region is a prime location for direct or indirect disruption of Hsp70 function.

Funding: LX was supported by a John and Pat Hume PhD scholarship from Maynooth University. GWJ was supported by grant from Science Foundation Ireland (SFI/13/ISCA2845 and RFP/07/BIC493) and by the Health Research Board (RP/04/227). SP and HZ were supported by the National Natural Science Foundation of China 
(31770829, 31920103011) and the Ministry of Science and Technology of China (2017YFA0504000).

Author contributions: L.X, D.C and Z.H performed the experiments. L.X produced a first draft of the manuscript. G.W.J, S.P and S.D conceived the study, designed the experiments, and were responsible for research supervision. G.W.J produced the final draft of the manuscript which was edited and agreed upon by all authors. 


\section{References}

1. Flaherty KM, DeLuca-Flaherty C, McKay DB. Three-dimensional structure of the ATPase fragment of a 70K heat-shock cognate protein. Nature. 1990;346(6285):623-8.

2. Zhu X, Zhao X, Burkholder WF, Gragerov A, Ogata CM, Gottesman ME, et al. Structural analysis of substrate binding by the molecular chaperone DnaK. Science. 1996;272(5268):1606-14.

3. Bertelsen EB, Zhou H, Lowry DF, Flynn GC, Dahlquist FW. Topology and dynamics of the 10 kDa C-terminal domain of DnaK in solution. Protein Sci. 1999;8(2):343-54.

4. Gong $\mathrm{W}, \mathrm{Hu} \mathrm{W}, \mathrm{Xu} \mathrm{L}, \mathrm{Wu} \mathrm{H}, \mathrm{Wu}$ S, Zhang $\mathrm{H}$, et al. The C-terminal GGAP motif of Hsp70 mediates substrate recognition and stress response in yeast. J Biol Chem. 2018.

5. Bertelsen EB, Chang L, Gestwicki JE, Zuiderweg ER. Solution conformation of wild-type E. coli Hsp70 (DnaK) chaperone complexed with ADP and substrate. Proc Natl Acad Sci U S A. 2009;106(21):8471-6.

6. Mayer MP, Schroder H, Rudiger S, Paal K, Laufen T, Bukau B. Multistep mechanism of substrate binding determines chaperone activity of Hsp70. Nat Struct Biol. 2000;7(7):586-93.

7. Mayer MP, Gierasch LM. Recent advances in the structural and mechanistic aspects of Hsp70 molecular chaperones. J Biol Chem. 2019;294(6):2085-97.

8. Tyedmers J, Mogk A, Bukau B. Cellular strategies for controlling protein aggregation. Nat Rev Mol Cell Biol. 2010;11(11):777-88.

9. Calloni G, Chen T, Schermann SM, Chang HC, Genevaux P, Agostini F, et al. DnaK functions as a central hub in the E. coli chaperone network. Cell Rep. 2012;1(3):251-64.

10. Lotz SK, Knighton LE, Nitika, Jones GW, Truman AW. Not quite the SSAme: unique roles for the yeast cytosolic Hsp70s. Curr Genet. 2019;65(5):1127-34.

11. Verghese J, Abrams J, Wang Y, Morano KA. Biology of the heat shock response and protein chaperones: budding yeast (Saccharomyces cerevisiae) as a model system. Microbiol Mol Biol Rev. 2012;76(2):115-58.

12. Wickner RB, Masison DC. Evidence for two prions in yeast: [URE3] and [PSI]. Curr Top Microbiol Immunol. 1996;207:147-60.

13. Jung $G$, Jones $G$, Wegrzyn RD, Masison DC. A role for cytosolic hsp70 in yeast [PSI(+)] prion propagation and [PSI(+)] as a cellular stress. Genetics. 2000;156(2):559-70.

14. Jones GW, Masison DC. Saccharomyces cerevisiae Hsp70 mutations affect [PSI+] prion propagation and cell growth differently and implicate $\mathrm{Hsp} 40$ and tetratricopeptide repeat cochaperones in impairment of [PSI+]. Genetics. 2003;163(2):495-506.

15. Jones G, Song Y, Chung S, Masison DC. Propagation of Saccharomyces cerevisiae [PSI+] prion is impaired by factors that regulate Hsp70 substrate binding. Mol Cell Biol. 2004;24(9):392837.

16. Wickner RB. [URE3] as an altered URE2 protein: evidence for a prion analog in Saccharomyces cerevisiae. Science. 1994;264(5158):566-9.

17. Jones GW, Tuite MF. Chaperoning prions: the cellular machinery for propagating an infectious protein? Bioessays. 2005;27(8):823-32.

18. Chernoff YO, Lindquist SL, Ono B, Inge-Vechtomov SG, Liebman SW. Role of the chaperone protein Hsp104 in propagation of the yeast prion-like factor [psi+]. Science. 1995;268(5212):880-4.

19. Matveenko AG, Barbitoff YA, Jay-Garcia LM, Chernoff YO, Zhouravleva GA. Differential effects of chaperones on yeast prions: CURrent view. Curr Genet. 2018;64(2):317-25.

20. Xu L, Gong W, Zhang H, Perrett S, Jones GW. The same but different: the role of Hsp70 in heat shock response and prion propagation. Prion. 2018;12(3-4):170-4. 
21. Masison DC, Kirkland PA, Sharma D. Influence of Hsp70s and their regulators on yeast prion propagation. Prion. 2009;3(2):65-73.

22. Panaretou B, Jones GW. Yeast models for amyloid disease. Essays Biochem. 2014;56:85-97.

23. Loovers HM, Guinan E, Jones GW. Importance of the Hsp70 ATPase domain in yeast prion propagation. Genetics. 2007;175(2):621-30.

24. Xu L, Gong W, Cusack SA, Wu H, Loovers HM, Zhang H, et al. The beta6/beta7 region of the Hsp70 substrate-binding domain mediates heat-shock response and prion propagation. Cell Mol Life Sci. 2017.

25. Kityk R, Vogel M, Schlecht R, Bukau B, Mayer MP. Pathways of allosteric regulation in Hsp70 chaperones. Nat Commun. 2015;6:8308.

26. Sondheimer N, Lopez N, Craig EA, Lindquist $\mathrm{S}$. The role of Sis1 in the maintenance of the [RNQ+] prion. EMBO J. 2001;20(10):2435-42.

27. Xu L, Hasin N, Shen M, He J, Xue Y, Zhou X, et al. Using steered molecular dynamics to predict and assess Hsp70 substrate-binding domain mutants that alter prion propagation. PLoS Comput Biol. 2013;9(1):e1002896.

28. Mandal SS, Merz DR, Buchsteiner M, Dima RI, Rief M, Zoldak G. Nanomechanics of the substrate binding domain of Hsp70 determine its allosteric ATP-induced conformational change. Proc Natl Acad Sci U S A. 2017;114(23):6040-5.

29. Rowlands MG, Newbatt YM, Prodromou C, Pearl LH, Workman P, Aherne W. High-throughput screening assay for inhibitors of heat-shock protein 90 ATPase activity. Anal Biochem. 2004;327(2):176-83.

30. Kamada Y, Jung US, Piotrowski J, Levin DE. The protein kinase C-activated MAP kinase pathway of Saccharomyces cerevisiae mediates a novel aspect of the heat shock response. Genes Dev. 1995;9(13):1559-71.

31. Xu L, Nitika, Hasin N, Cuskelly DD, Wolfgeher D, Doyle S, et al. Rapid deacetylation of yeast Hsp70 mediates the cellular response to heat stress. Sci Rep. 2019;9(1):16260.

32. Van Der Spoel D, Lindahl E, Hess B, Groenhof G, Mark AE, Berendsen HJ. GROMACS: fast, flexible, and free. J Comput Chem. 2005;26(16):1701-18.

33. Stevens SY, Cai S, Pellecchia M, Zuiderweg ER. The solution structure of the bacterial HSP70 chaperone protein domain DnaK(393-507) in complex with the peptide NRLLLTG. Protein Sci. 2003;12(11):2588-96.

34. Guex N, Peitsch MC. SWISS-MODEL and the Swiss-PdbViewer: an environment for comparative protein modeling. Electrophoresis. 1997;18(15):2714-23.

35. Lee DH, Goldberg AL. Selective inhibitors of the proteasome-dependent and vacuolar pathways of protein degradation in Saccharomyces cerevisiae. J Biol Chem. 1996;271(44):27280-4.

36. Nagano N, Ota M, Nishikawa K. Strong hydrophobic nature of cysteine residues in proteins. FEBS Lett. 1999;458(1):69-71.

37. O'Brien MC, McKay DB. Threonine 204 of the chaperone protein Hsc70 influences the structure of the active site, but is not essential for ATP hydrolysis. J Biol Chem. 1993;268(32):24323-9.

38. Solis EJ, Pandey JP, Zheng X, Jin DX, Gupta PB, Airoldi EM, et al. Defining the Essential Function of Yeast Hsf1 Reveals a Compact Transcriptional Program for Maintaining Eukaryotic Proteostasis. Mol Cell. 2016;63(1):60-71.

39. Abravaya K, Myers MP, Murphy SP, Morimoto RI. The human heat shock protein hsp70 interacts with HSF, the transcription factor that regulates heat shock gene expression. Genes Dev. 1992;6(7):1153-64. 
40. Morimoto RI, Santoro MG. Stress-inducible responses and heat shock proteins: new pharmacologic targets for cytoprotection. Nat Biotechnol. 1998;16(9):833-8.

41. Bettencourt BR, Feder ME, Cavicchi S. Experimental Evolution of Hsp70 Expression and Thermotolerance in Drosophila Melanogaster. Evolution. 1999;53(2):484-92.

42. Gupta A, Puri A, Singh P, Sonam S, Pandey R, Sharma D. The yeast stress inducible Ssa Hsp70 reduces alpha-synuclein toxicity by promoting its degradation through autophagy. PLoS Genet. 2018;14(10):e1007751.

43. Sharma D, Masison DC. Functionally redundant isoforms of a yeast Hsp70 chaperone subfamily have different antiprion effects. Genetics. 2008;179(3):1301-11.

44. Vivian JP, Hastings AF, Duggin IG, Wake RG, Wilce MC, Wilce JA. The impact of single cysteine residue mutations on the replication terminator protein. Biochem Biophys Res Commun. 2003;310(4):1096-103.

45. Loyola C, Saavedra C, Gomez I, Vasquez C. The amino acidic substitution of cysteine 167 by serine (C167S) in BstVI restriction endonuclease of Bacillus stearothermophilus $V$ affects its conformation and thermostability. Biochimie. 1999;81(3):261-6.

46. Lee EM, Lee SS, Tripathi BN, Jung HS, Cao GP, Lee $Y$, et al. Site-directed mutagenesis substituting cysteine for serine in 2-Cys peroxiredoxin (2-Cys Prx A) of Arabidopsis thaliana effectively improves its peroxidase and chaperone functions. Ann Bot. 2015;116(4):713-25.

47. Fremaux I, Mazeres S, Brisson-Lougarre A, Arnaud M, Ladurantie C, Fournier D. Improvement of Drosophila acetylcholinesterase stability by elimination of a free cysteine. BMC Biochem. 2002;3:21.

48. Amaki $\mathrm{Y}$, Nakano $\mathrm{H}$, Yamane T. Role of cysteine residues in esterase from Bacillus stearothermophilus and increasing its thermostability by the replacement of cysteines. Appl Microbiol Biotechnol. 1994;40(5):664-8.

49. Peng J, Schwartz D, Elias JE, Thoreen CC, Cheng D, Marsischky G, et al. A proteomics approach to understanding protein ubiquitination. Nat Biotechnol. 2003;21(8):921-6.

50. Swaney DL, Beltrao P, Starita L, Guo A, Rush J, Fields S, et al. Global analysis of phosphorylation and ubiquitylation cross-talk in protein degradation. Nat Methods. 2013;10(7):676-82.

51. Moore DJ, West AB, Dikeman DA, Dawson VL, Dawson TM. Parkin mediates the degradationindependent ubiquitination of Hsp70. J Neurochem. 2008;105(5):1806-19.

52. Qian SB, McDonough H, Boellmann F, Cyr DM, Patterson C. CHIP-mediated stress recovery by sequential ubiquitination of substrates and Hsp70. Nature. 2006;440(7083):551-5.

53. Buchberger A, Theyssen H, Schroder H, McCarty JS, Virgallita G, Milkereit P, et al. Nucleotideinduced conformational changes in the ATPase and substrate binding domains of the DnaK chaperone provide evidence for interdomain communication. J Biol Chem. 1995;270(28):16903-10.

54. Needham PG, Masison DC. Prion-impairing mutations in Hsp70 chaperone Ssa1: effects on ATPase and chaperone activities. Arch Biochem Biophys. 2008;478(2):167-74.

55. Goldberg AL. Protein degradation and protection against misfolded or damaged proteins. Nature. 2003;426(6968):895-9.

56. Christiano R, Nagaraj N, Frohlich F, Walther TC. Global proteome turnover analyses of the Yeasts S. cerevisiae and S. pombe. Cell Rep. 2014;9(5):1959-65.

57. Mayer MP, Kityk R. Insights into the molecular mechanism of allostery in Hsp70s. Front Mol Biosci. 2015;2:58. 


\section{Figures}

Fig. 1. Evolutionarily conserved residue 475 mediates cellular functions of Hsp70. (A) Alignment of Hsp70 proteins from yeast, human and E. coli. (B) The residue Phe475 is adjacent to the substrate-binding pocket on Ssa1. Phe475 is shown in red on the Ssa1 structure (PDB: $5 \mathrm{Z} 8 \mathrm{I})$. (C) $\left[\mathrm{PSI}^{+}\right]$prion propagation in Ssa mutants. A single colony with sole Ssa source containing homologue F475S variant was streaked onto YPD and -ADE plates and grown for 2 days at $30^{\circ} \mathrm{C}$. [ $\left.p s i^{-}\right]$cells produce red colonies on YPD and do not grow on $-\mathrm{ADE}$ plates. $\left[\mathrm{PSI}^{+}\right]$cells produce white colonies on YPD and grow on $-\mathrm{ADE}$ plates. (D) Temperature sensitivity of Ssa mutants. Cells expressing WT Ssa or corresponding F475S homologues as their sole Ssa protein were spotted in a 1/5 serial dilution onto YPD and were incubated for 2 days at $30^{\circ} \mathrm{C}, 37^{\circ} \mathrm{C}$ or $39^{\circ} \mathrm{C}$.

Fig. 2. Specific SBD cleavage induced by F475S mutation. (A) G402 cells containing N-Flag tagged or tag-free vector were homogenized and precipitated by anti-Flag beads. Anti-Flag was used to probe Flag-tagged Ssa1 proteins and degraded fragments. (B) Effects of degradation inhibitors on the abundance of F475S protein. Western blotting was performed to assess the protein levels of Ssa1 F475S following treatment with MG132 (75 $\mu \mathrm{M})$ or PMSF (1 mM). DMSO was used to dissolve MG132 and PMSF, and the same volume of DMSO was added as a negative control in cell cultures. A stained SDS-PAGE gel running under the same conditions was used as the loading control. Two independent experiments were performed. (C) Vacuolar carboxypeptidase (Pep4) is primarily responsible for degradation of the SBD. The F475S variant was transformed into $\triangle P E P 4$, $\triangle U F D 2$ and $\triangle U B I 4$ cells. After immunoprecipitation, anti-Flag was used to probe Flagtagged Ssa1 proteins and degraded fragments.

Fig. 3. Phenotypes of different Phe475 substitutions. (A) Assessments of $\left[\mathrm{PSI}^{+}\right]$ propagation; [ $\left.\mathrm{psi}^{-}\right]$cells produce red colonies on YPD and are unable to grow on -ADE plates; $\left[\mathrm{PSI}^{+}\right]$cells produce white colonies on YPD and grow on -ADE plates. (B) Growth 
assay of Phe475 mutations at elevated temperatures. Cells expressing WT Ssal or corresponding Phe475 mutations as their sole Ssa protein were spotted in a 1/5 serial dilution onto YPD, and were incubated for 2 days at $30^{\circ} \mathrm{C}, 37^{\circ} \mathrm{C}$ or $39^{\circ} \mathrm{C}$. (C) Growth assay of Phe475 mutations under other stresses. YPD or SC medium was supplemented with cell-wall damage agent SDS or oxidative damage agent $\mathrm{H}_{2} \mathrm{O}_{2}$ respectively to achieve the required concentrations. (D) Acquired thermotolerance assay of Phe475 mutations. Fresh cultures were pre-treated at $39{ }^{\circ} \mathrm{C}$ for $1 \mathrm{~h}$, then cells were heat shocked at $47{ }^{\circ} \mathrm{C}$ for the indicated times before spotting onto YPD.

Fig. 4. Amino acid substitutions at residues 475 alter Hsp70 SBDß conformation and stability. (A) The elution pattern of SBD truncation proteins. Size exclusion chromatography (SEC) was performed at RT. (B) The stability of SBD truncation proteins. Recombinant proteins were incubated at $30{ }^{\circ} \mathrm{C}$ for $24 \mathrm{~h}$ and then size exclusion chromatography (SEC) was performed at RT. (C) CD spectroscopy of SBD truncation proteins at $30^{\circ} \mathrm{C}$. (D) Secondary structure monitored by far-UV CD spectra for full-length Ssa1 at $30^{\circ} \mathrm{C}$.

Fig. 5. Variants at residue 475 alter ATPase activity of Ssa1. (A) The ATPase activity of the full-length Ssal proteins. ATPase assay was performed at $30^{\circ} \mathrm{C}, 37^{\circ} \mathrm{C}$ or $39^{\circ} \mathrm{C}$. (B) ATPase activity stimulated by Ydj1. (C) ATPase activity stimulated by addition of peptide. The unit of the ATP turnover rate is $\min ^{-1}$. The values shown are the mean of four or eight replicates from independent measurements and the error bars represent the standard deviation. (D) Specific SBD cleavage during heat shock. WT cells were grown at $39^{\circ} \mathrm{C}$ for times as indicated (left panel) or cultured in SC containing $300 \mu \mathrm{g} / \mathrm{ml} \mathrm{AZC} \mathrm{for} 2 \mathrm{~h}$ (right panel). After Flag-Ssa1 precipitation, Anti-Flag was used to probe Flag-tagged Ssa1 proteins.

Fig. 6. Variants at residue 475 alter functions of Ssa1. (A) Luciferase refolding activity of Phe 475 mutations in vivo. Fresh cultures were shifted to $37{ }^{\circ} \mathrm{C}$ for $30 \mathrm{~min}$ before $45^{\circ} \mathrm{C}$ denaturation for $1 \mathrm{~h}$. Denatured luciferase cultures were recovered at $25^{\circ} \mathrm{C}$ for a $1 \mathrm{~h}$ period. 
Cycloheximide was added to prevent protein synthesis during the recovery period. (B) Chaperone abundance of the Hsp70 machinery. Western blotting was performed to assess the abundance of Hsp104, Ssa1 and Ydj1. GAPDH and a stained SDS-PAGE ran under the same conditions were used as loading controls. Protein content was normalized to GAPDH (protein/GAPDH ratio).

Fig. 7. Substitutions of residue 483 alter molecular and cellular functions of Ssa1. (A) Growth assay of Leu483 mutations at elevated temperatures. Cells expressing WT Ssa1 or corresponding Leu483 mutations as their sole Ssa protein were spotted in a 1/5 serial dilution onto YPD and then incubated for 2 days at $30^{\circ} \mathrm{C}, 37^{\circ} \mathrm{C}$ or $39^{\circ} \mathrm{C}$. (B) Luciferase refolding activity of Leu483 mutant yeast strains. Fresh cultures were shifted to $37^{\circ} \mathrm{C}$ for $30 \mathrm{~min}$ before $45^{\circ} \mathrm{C}$ denaturation for $1 \mathrm{~h}$. Denatured luciferase cultures were allowed to recover at $25^{\circ} \mathrm{C}$ for a $1 \mathrm{~h}$ period. Cycloheximide was added to prevent protein synthesis during the recovery period. (C) The ATPase activity of the full-length Ssal proteins. ATPase assay was performed at $30^{\circ} \mathrm{C}, 37^{\circ} \mathrm{C}$ or $39^{\circ} \mathrm{C}$ with stimulation by Ydj1 or peptide. The unit of the ATP turnover rate is $\mathrm{min}^{-1}$. The values shown are the mean of four replicates from independent measurements and the error bars represent the standard deviation. (D) Chaperone abundance of the Hsp70 machinery. Western blotting was performed to assess the expression levels of Hsp104, Ssa1 and Ydj1. GAPDH and a stained SDS-PAGE run under the same conditions were used as loading controls. Protein content was normalized to GAPDH (protein/GAPDH ratio).

Fig. 8. Amino acid substitutions at residue 483 alter Hsp70 SBDß conformation and stability. (A) CD spectra of SBD truncation proteins at $30{ }^{\circ} \mathrm{C}$. (B) Secondary structure monitored by far-UV CD for full-length Ssa1 at $30^{\circ} \mathrm{C}$. (C) RMSD (root-mean-square deviation) of the side chain of 483 as a function of simulation. (D) Superposition of residue 483 snapshots of every $1 \mathrm{~ns}$ during simulations. The $0 \mathrm{~ns}$ point is highlighted in bold black. 
Table 1. Amino-Acid Properties of Residue 475

\begin{tabular}{ccccc}
\hline $\begin{array}{c}\text { Amino Acid at } \\
\text { Residue 475 }\end{array}$ & $\begin{array}{c}\text { Size of the } \\
\text { Side Chain }\end{array}$ & $\begin{array}{c}\text { Polar/Nonpolar } \\
(+/-)\end{array}$ & {$\left[P S I^{+}\right] /\left[p^{i}\right]$} & $\begin{array}{c}\text { Temperature } \\
\text { Sensitive }\end{array}$ \\
\hline Phe & + & - & + & $\mathrm{N}$ \\
Ser & -- & + & - & $\mathrm{Y}$ \\
Ala & --- & - & - & $\mathrm{Y}$ \\
Cys & - & $+/-$ & + & $\mathrm{N}$ \\
Trp & +++ & - & $\mathrm{NA}$ & $\mathrm{NA}$ \\
Tyr & ++ & - & + & $\mathrm{N}$ \\
\hline
\end{tabular}


Fig 1

A

C

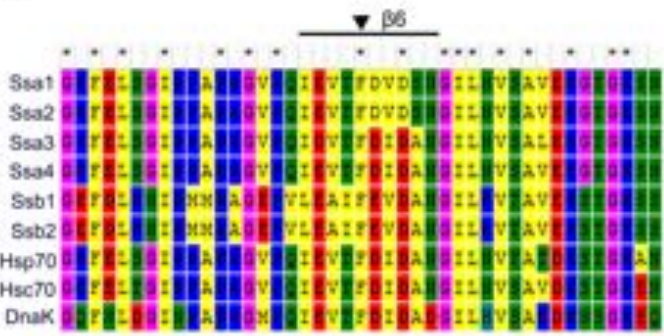

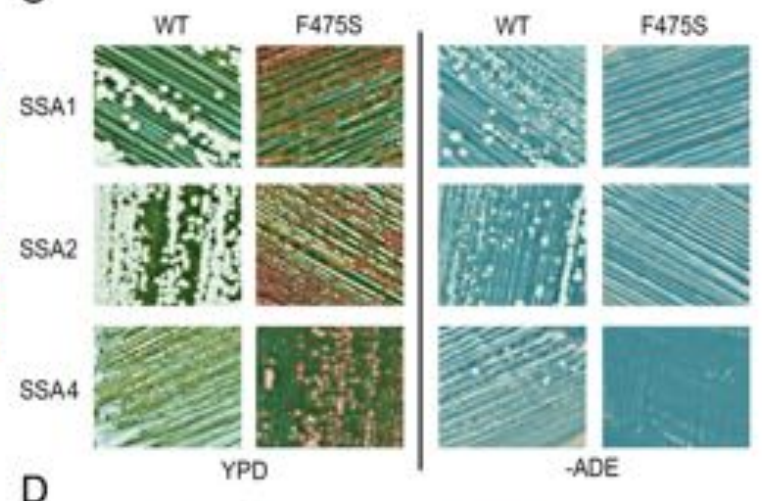

B

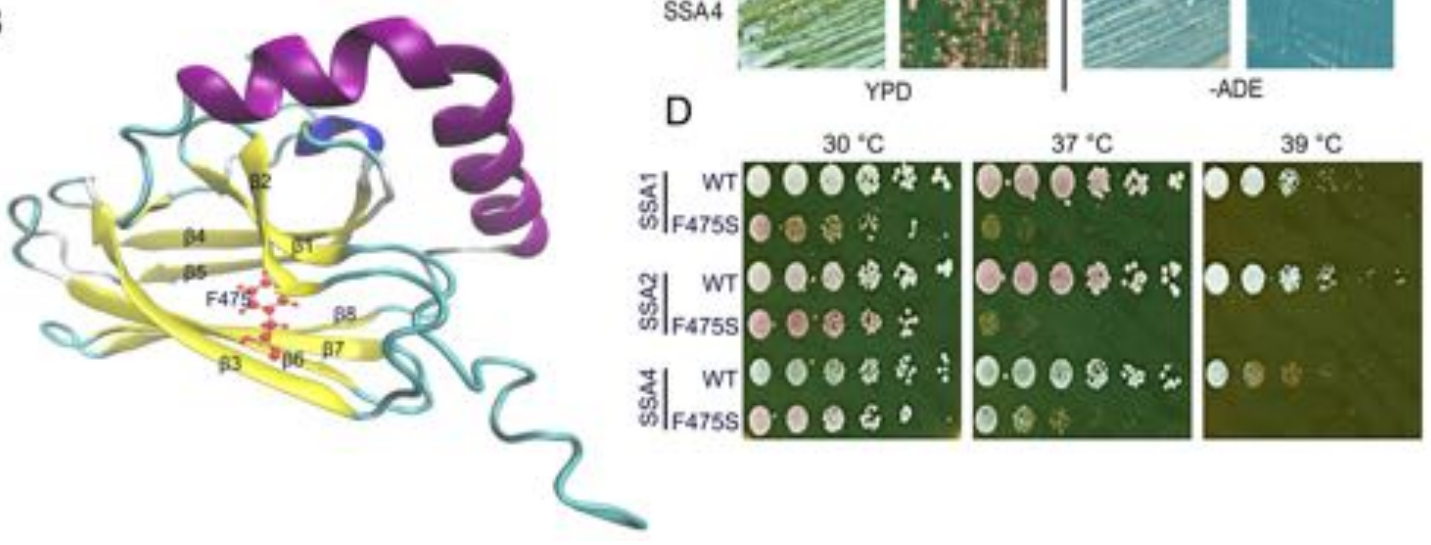


Fig 2

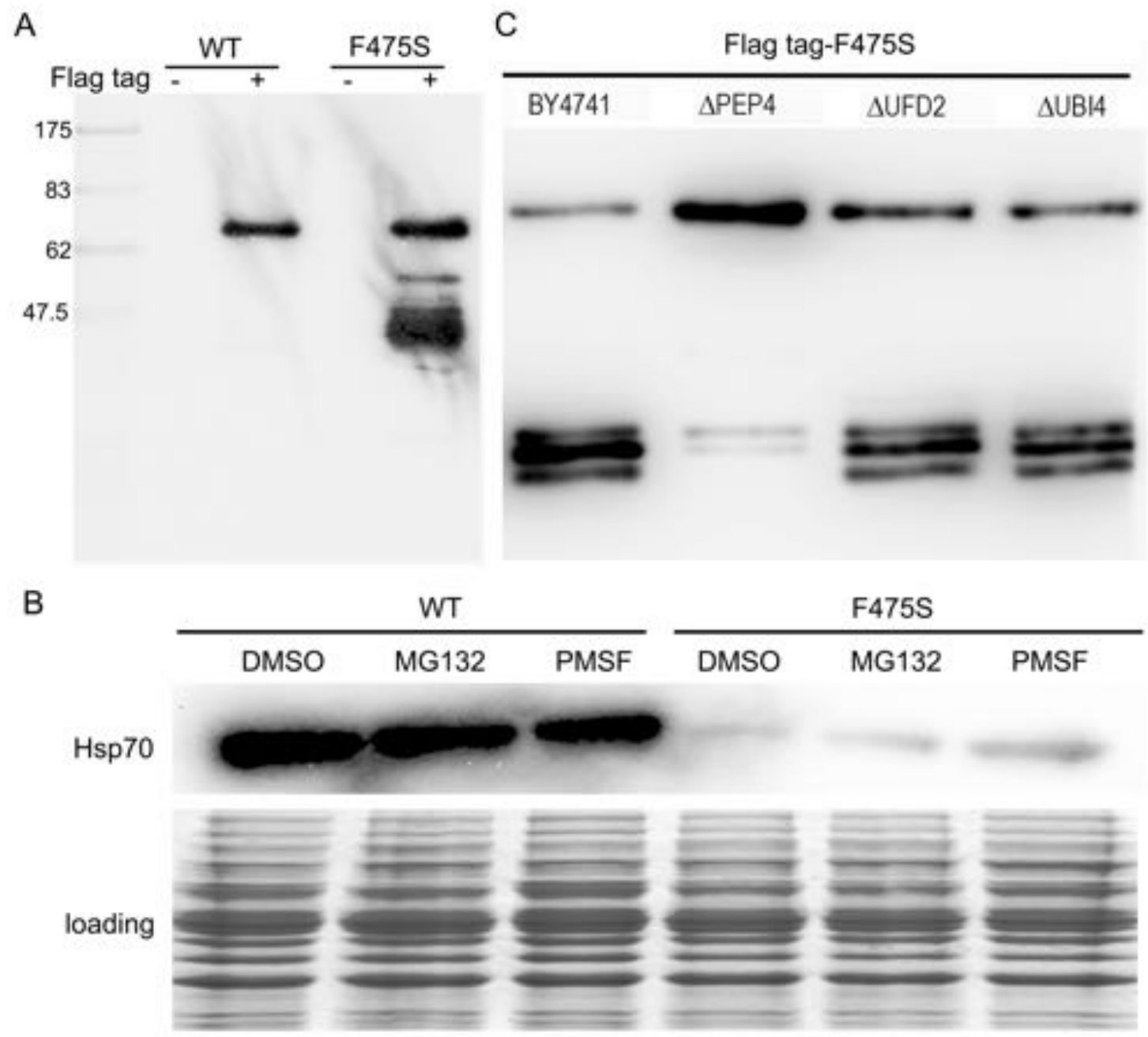


Fig 3

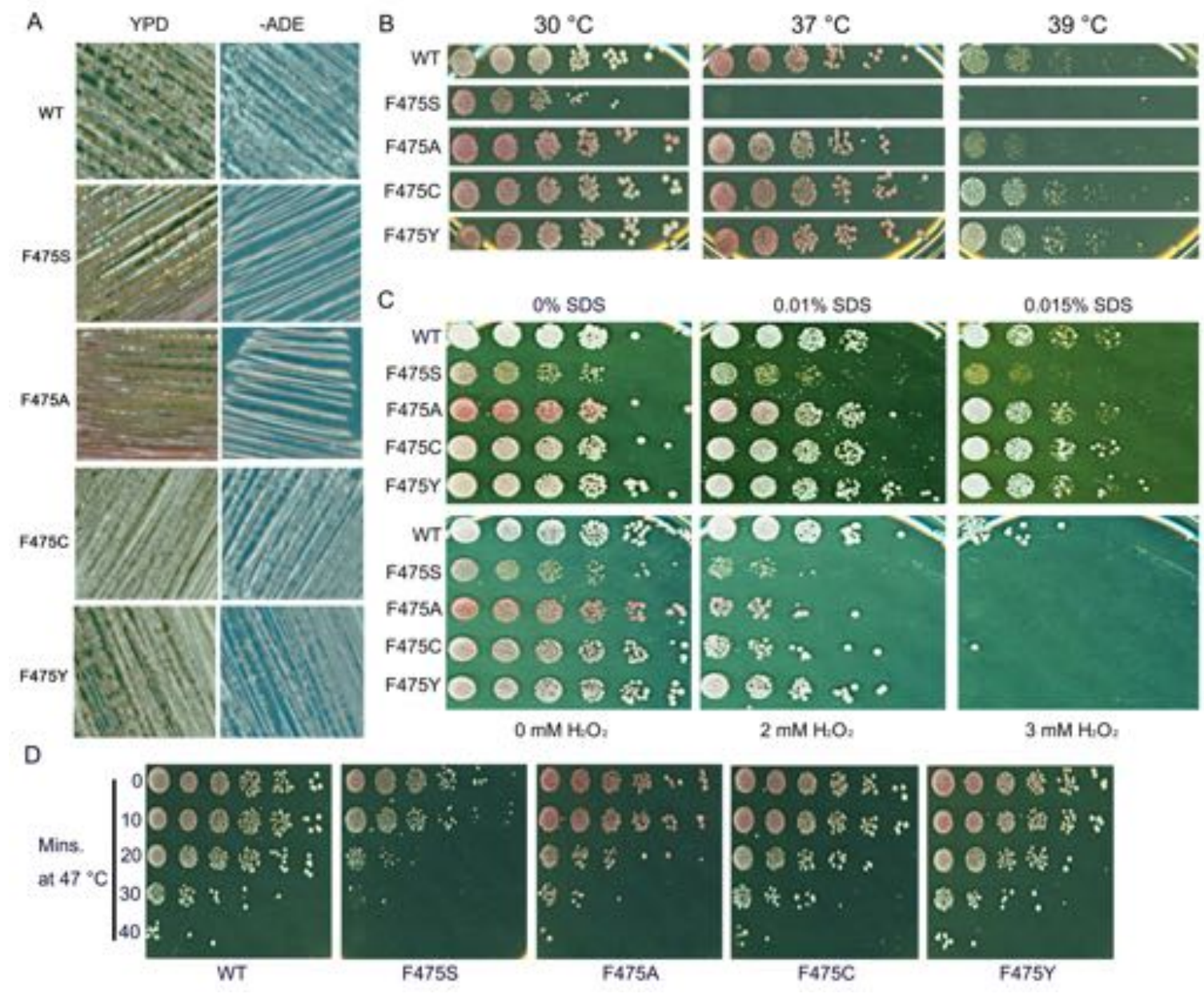


Fig 4

A

B
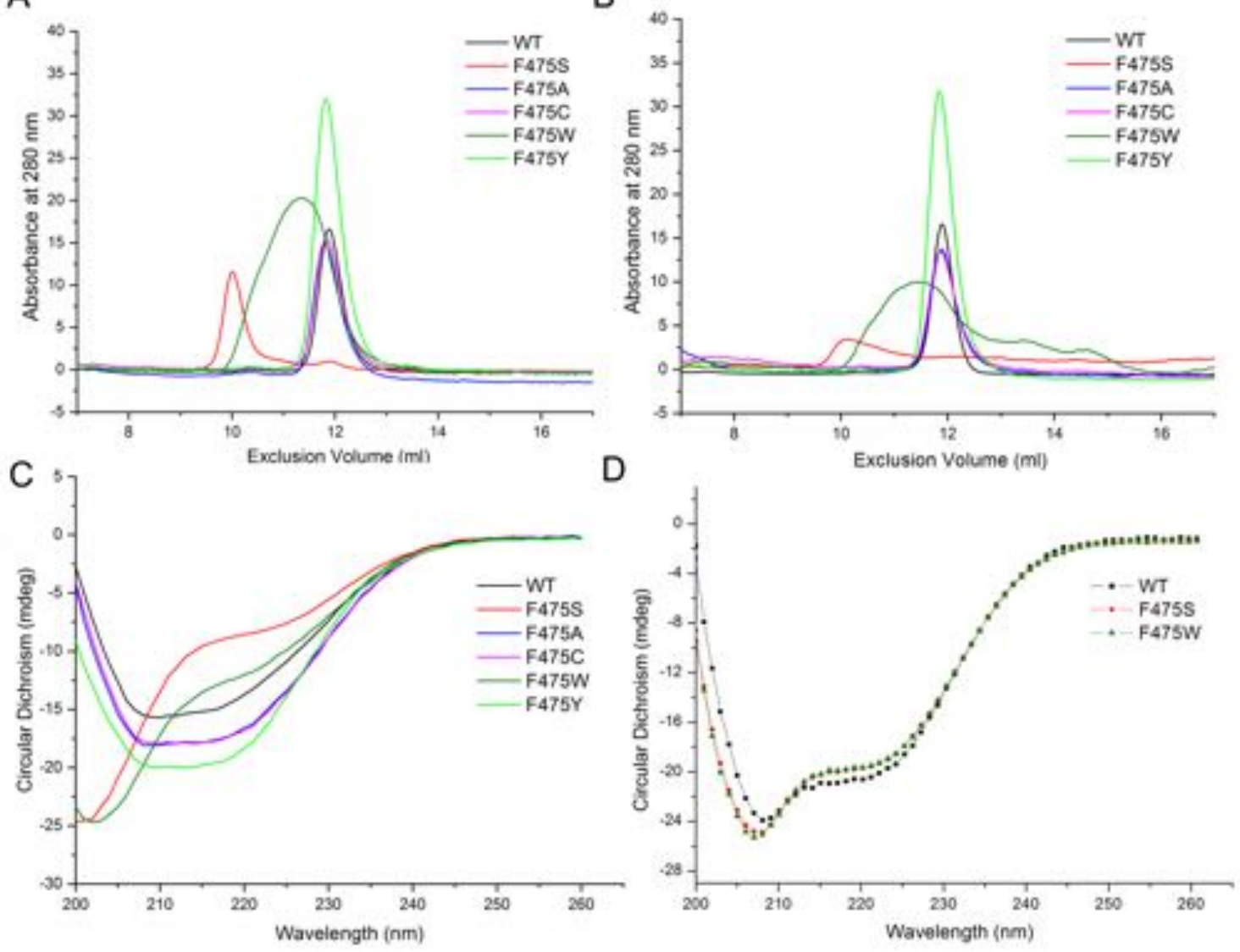
Fig 5

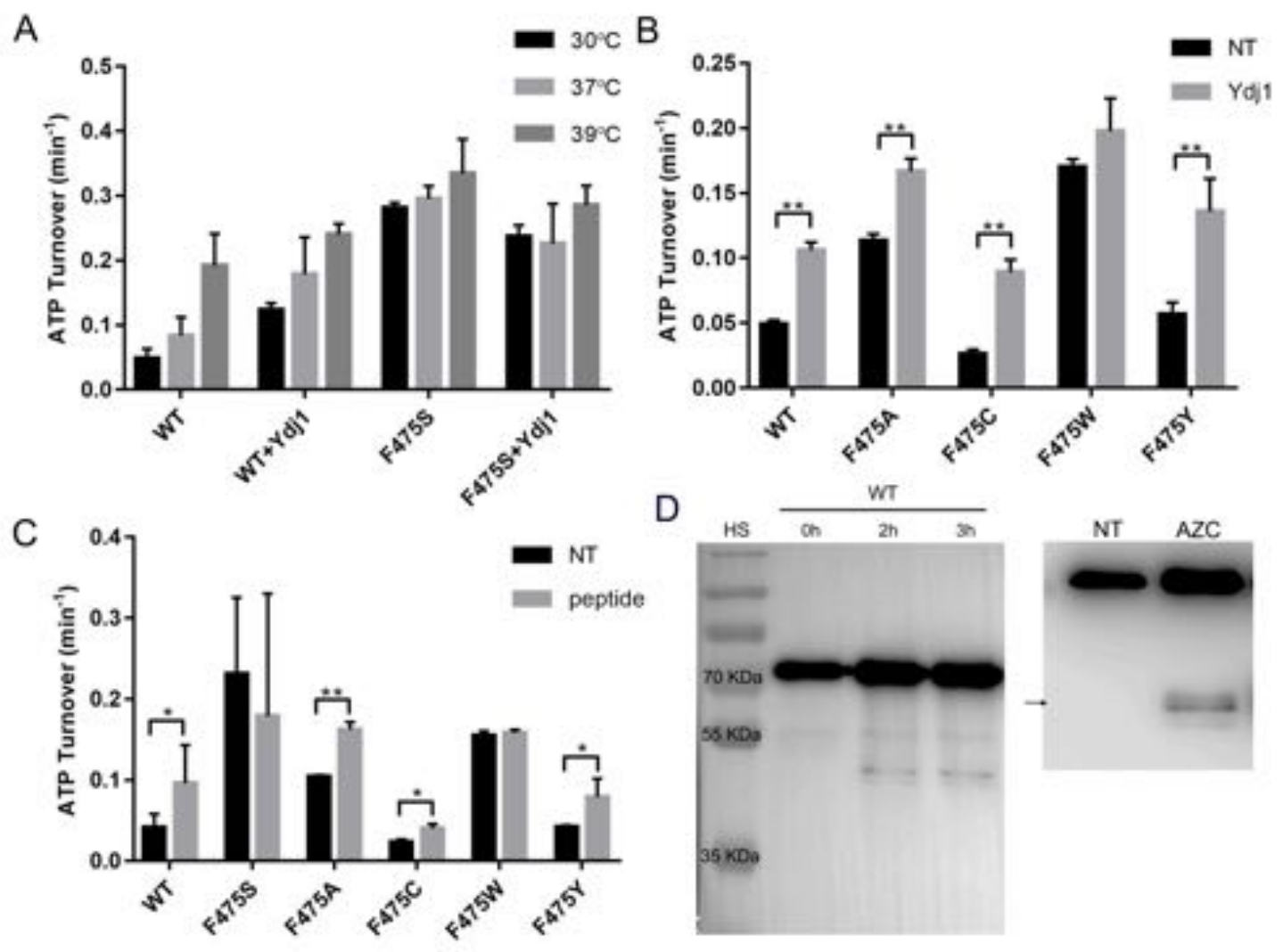


Fig 6

A

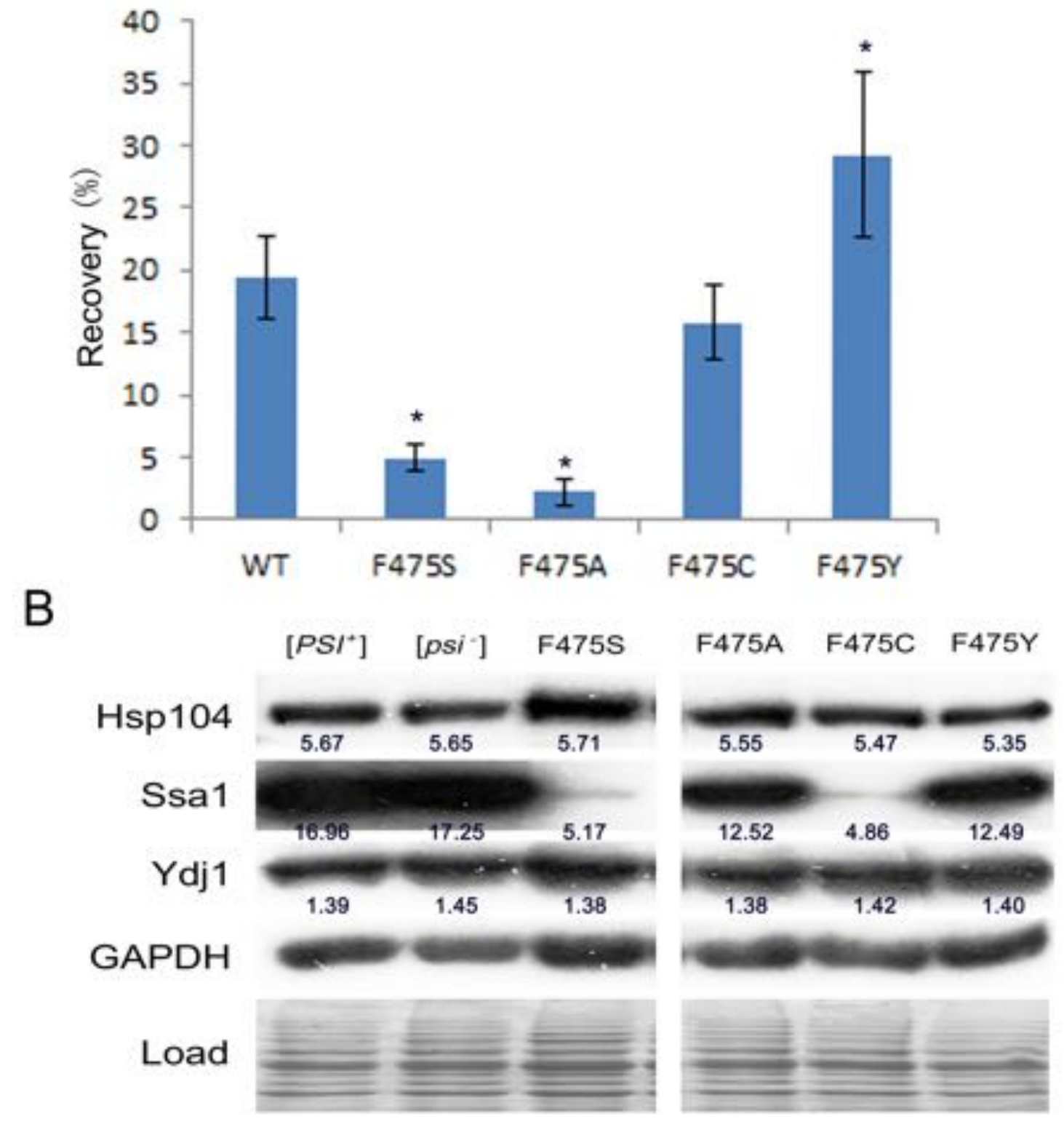


Fig 7
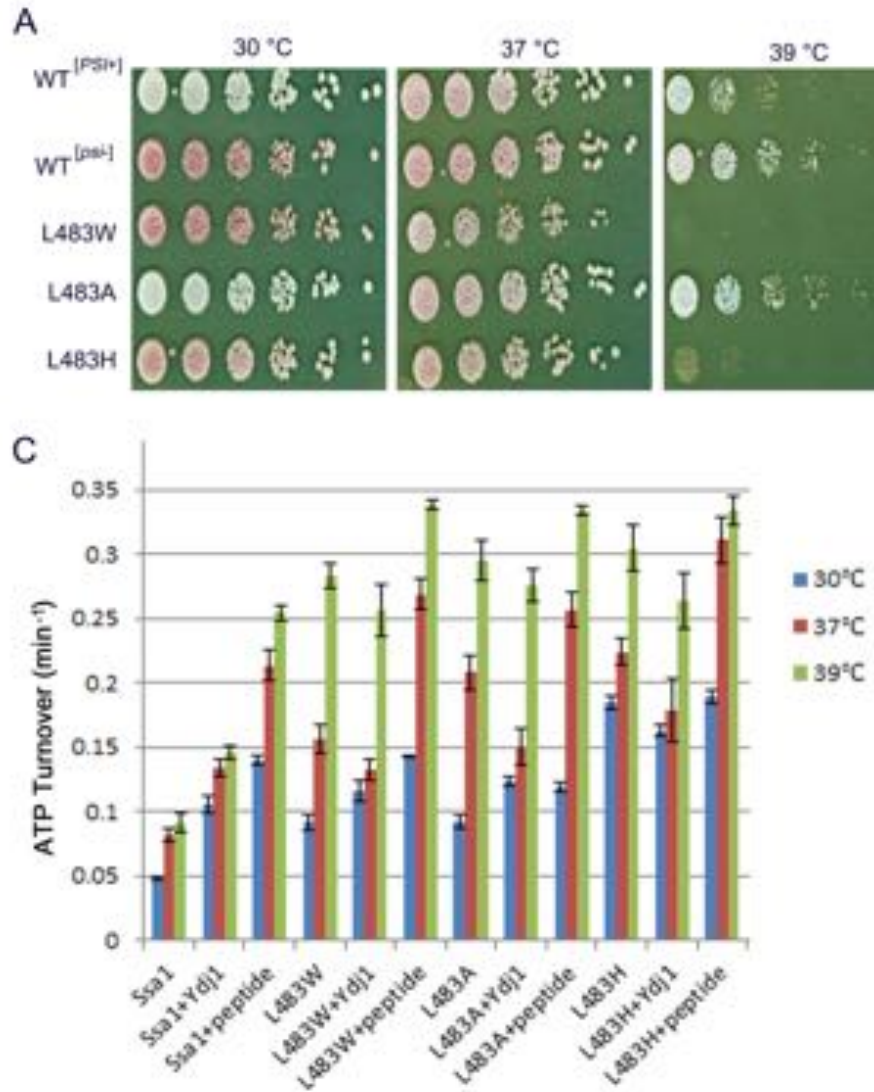

B
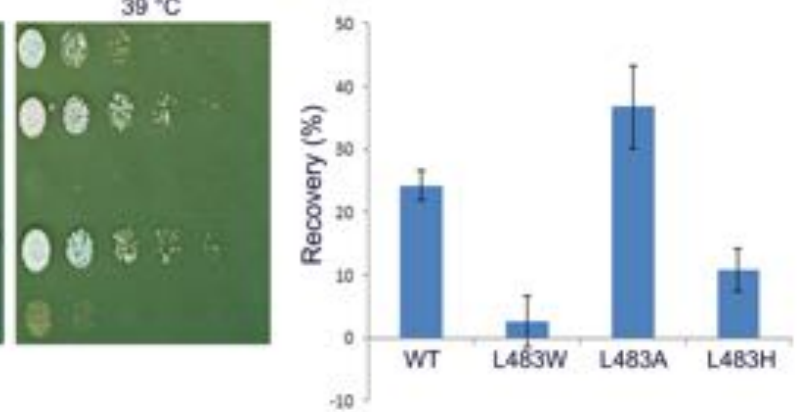

D

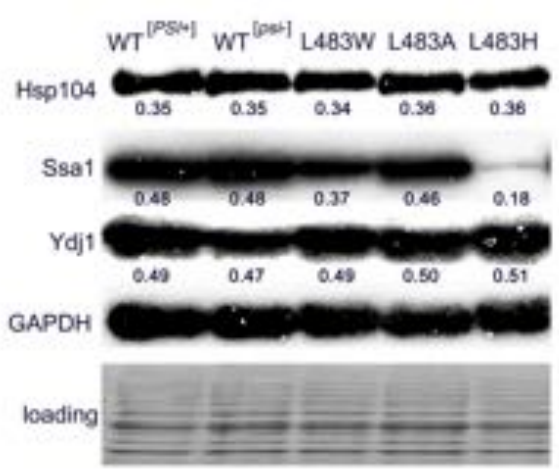


Fig 8
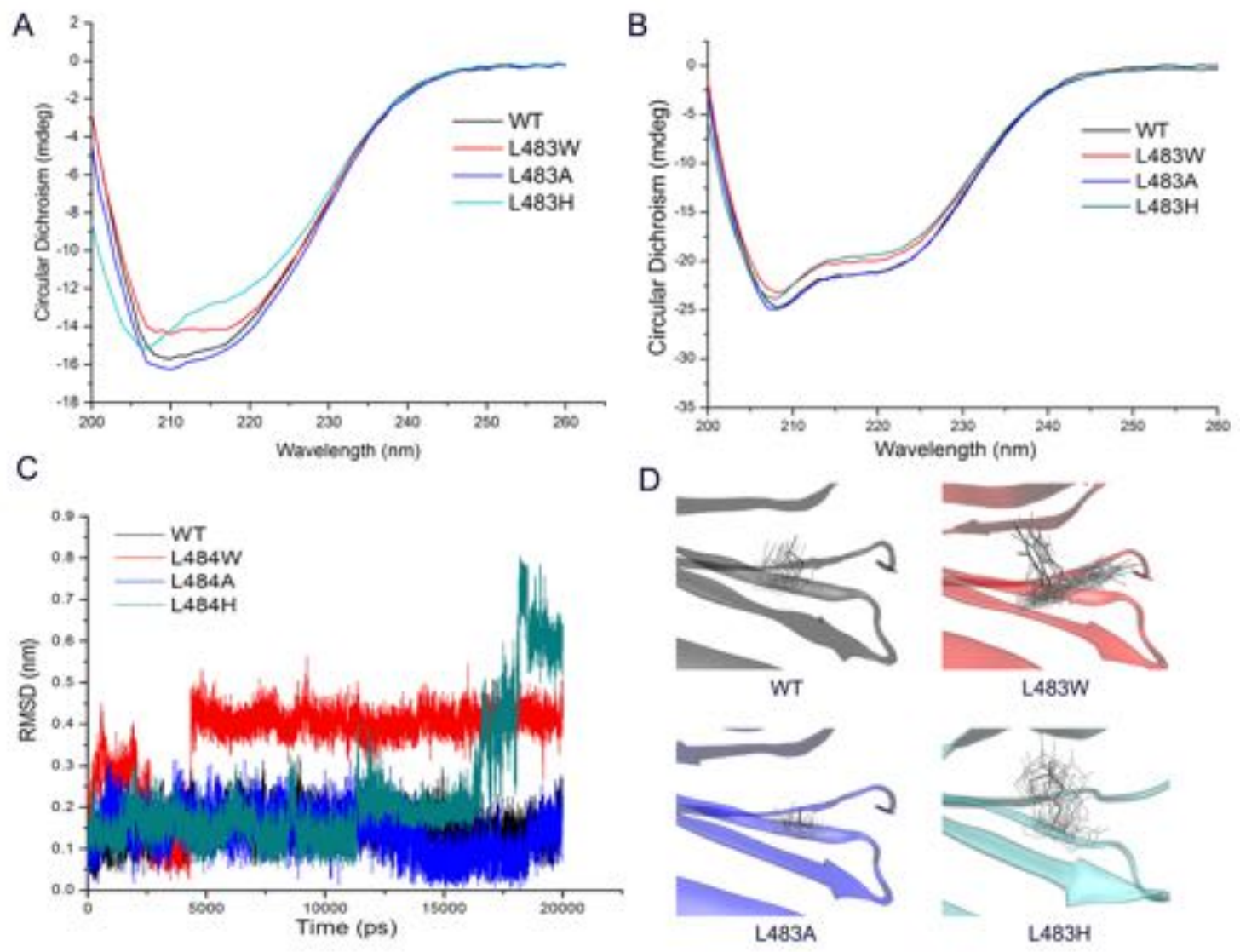